\title{
Impact of a Single Session of Inhalation Technique Training on Inhalation Skills and the Course of Asthma and COPD
}

\author{
Marta Dabrowska, Katarzyna Luczak-Wozniak, Marta Miszczuk, Izabela Domagala, \\ Wojciech Lubanski, Andrzej Leszczynski, Marta Maskey-Warzechowska, Renata Rubinsztajn, \\ Joanna Hermanowicz-Salamon, and Rafal Krenke
}

\begin{abstract}
BACKGROUND: A significant percentage of patients with asthma and COPD do not use their inhalers properly. The aim of this study was to evaluate the impact of a single session of inhalation technique training on the frequency of inhalation errors and the course of asthma and COPD. METHODS: This randomized controlled trial included adults who had been diagnosed with and treated for asthma or COPD with at least one inhaler use daily on a regular basis. All subjects were followed for 6 months, at which time their inhalation technique was assessed and an individual inhalation training (study group) or a sham procedure (control group) was applied. The number of mishandlings was calculated as the ratio of the number of errors to the number of inhalers used by an individual subject. The effect of training was evaluated after 3 months and again after 6 months. RESULTS: 50 subjects with asthma and 50 subjects with COPD were enrolled. Only $20 \%$ of subjects made no critical errors before the intervention. Subjects who were trained in the proper inhalation technique made fewer errors after 3 months (32 of 50 vs 20 of 50). The relative risk was $1.63(95 \%$ CI 1.1-2.4, $P=.01)$ and the number needed to treat was 3.9 (95\% CI 2.2-15). Despite the improvement in the inhalation technique, we found no reduction in the number of asthma/COPD exacerbations, symptom severity, or the quality of life. After 3 consecutive months, the efficacy of the intervention decreased, and only $66 \%$ of the former responders maintained the lower ratio of errors per inhaler. After 6 months, there was no difference in the number of subjects with better inhalation technique between intervention (24 of 50) and control group (27 of 50) $(P=.62)$. CONCLUSIONS: Although a single inhalation training leads to a reduction in the number of errors made during inhalation, it does not influence the course of asthma and COPD. The positive effect of a single inhalation technique training is temporary. (ClinicalTrials.gov registration NCT02131454.) Key words: asthma; COPD; inhaler; inhalation technique; inhalation errors; training of inhalation technique. [Respir Care 2019;64(10):1250-1260. @ 2019 Daedalus Enterprises]
\end{abstract}

\section{Introduction}

Inhaled therapy is the cornerstone of treatment in asthma and COPD. Inhaled administration of drugs has considerable advantages over systemic therapy. It allows drug de-

Drs Dabrowska, Maskey-Warzechowska, Rubinsztajn, HermanowiczSalamon, and Krenke are affiliated with the Department of Internal Medicine, Pulmonary Diseases and Allergy, Medical University of Warsaw, Poland. Drs Luczak-Wozniak, Miszczuk, Domagala, Lubanski, and Leszczynski are affiliated with the Students' Research Group Alveolus, Medical University of Warsaw, Poland.

A version of this paper was presented as a poster at the European Respiratory Society International Congress, held September 9-13, 2017, in Milan, Italy. livery directly to the target site (ie, the lower airways), thus resulting in more rapid symptom alleviation and enabling the use of lower doses in comparison to systemic

\footnotetext{
Supplementary material related to this paper is available at http:// www.rcjournal.com.
}

The authors have disclosed no conflicts of interest.

Correspondence: Katarzyna Luczak-Wozniak MD, Department of Internal Medicine, Pulmonary Diseases and Allergy, Medical University of Warsaw, Banacha 1A, 02-097 Warsaw, Poland. E-mail: kasia. luczak1@gmail.com.

DOI: $10.4187 /$ respcare .06740 
treatment. The positive effects of inhaled therapy are influenced not only by the choice of treatment modality but also by the patient's inhalation technique. ${ }^{1-5}$ This depends on the type and number of inhalers prescribed and on the cognitive capabilities of the subject.

It appears that one of the most important factors influencing adherence to inhaled therapy is patient education and training on inhalation technique. , $^{1,3,5}$ For patients with obstructive lung diseases, experts recommend that inhalation technique and adherence should be evaluated before introducing changes to the patient's inhalation therapy. ${ }^{1,2}$ Despite the awareness of the problem of improper inhalation techniques, the issue has remained unresolved for decades. ${ }^{6}$ It has been reported that the number of errors made during inhalation is related to the number of different inhalers used concurrently. ${ }^{7}$ On the other hand, it is estimated that $25-31 \%$ of subjects using different inhaler devices have not been offered any training on inhalation technique. ${ }^{7}$ Paradoxically, the development of new userfriendly inhalers may not improve the situation because their use is restricted to the delivery of a specific compound and they do not eliminate inhalation errors while using other inhalers that require different inhalation techniques.

Improper inhalation technique is an important factor contributing to more severe courses of asthma and COPD. ${ }^{8}$ A number of studies have reported a positive correlation between the number of errors made during inhalation and the level of symptoms, as well as the rate of disease exacerbations. ${ }^{9-13}$ Studies have also documented the positive effect of different methods of education on the improvement of inhalation technique, ${ }^{8}$ although only a few were randomized, controlled trials. ${ }^{14-19}$ These studies differed in many aspects, including groups of trainers (eg, pharmacist, nurse, GP assistant, research educator), methods of training (eg, basic inhaler technique counseling, active showand-tell training, additional leaflets), population (eg, patients with asthma, patients with COPD, adults, children), and duration of the observation period (eg, 1 mo to $2 \mathrm{y}$ ). Although the results of these reports indicated that training leads to improvement in inhalation skills, the impact of training on symptoms or exacerbations of asthma and COPD was ambiguous. Some authors reported a decrease in asthma or COPD symptoms and exacerbation rate, ${ }^{14,16,18}$ whereas others failed to find a significant reduction in symptoms, health-related quality of life (HRQOL), and the number of exacerbations. ${ }^{15,19}$

Given the inconsistency of the available data, we undertook a study designed to determine the impact of a single session of inhalation technique training on the frequency of inhalation errors and the course of asthma and COPD. We assumed that a single session of inhalation training might lead to a decrease in the number of inhalation errors and improve treatment efficacy (ie, a reduc-

\section{QUICK LOOK}

\section{Current knowledge}

A significant percentage of patients with asthma and COPD do not use their inhalers properly. Improper inhalation technique may contribute to a more severe course of asthma or COPD.

\section{What this paper contributes to our knowledge}

A single session of training in inhalation technique led to a reduction in the number of inhalation errors, but not to an improvement in asthma or COPD control. The effect of a single session of training in inhalation technique was temporary. This indicates that methods to improve inhaler technique need to be repeated.

tion in the frequency of asthma/COPD exacerbations and improvement of HRQOL). Therefore, the specific aims of the study were as follows: to evaluate the impact of a single session of inhalation technique training on the number of inhalation errors; to evaluate the impact of a single session of inhalation technique training on the number of asthma/COPD exacerbations and HRQOL; and to characterize subjects who do not respond to inhalation training.

\section{Methods}

\section{General Study Design}

This was a prospective, single-center, randomized controlled trial with a 1:1 allocation to an arm with inhalation technique training combined with basic asthma/COPD education or an arm with basic education only (Fig. 1). Each subject was observed for 12 months: 6 months before the intervention and 6 months after the intervention (Fig. 2). The intervention consisted of a single individual training session on proper inhalation technique and basic education about asthma or COPD. The control subjects received basic education about asthma or COPD, but their inhalation technique was not corrected (single-blinded protocol).

The primary end point was the reduction in the number of errors made during inhalation. The secondary end points were a reduction in the number of moderate or severe exacerbations of asthma and COPD, a reduction in the level of asthma and COPD symptoms, and an improvement in HRQOL.

The study was approved by the Institutional Review Board (KB 43/2013). All subjects signed an informed consent to participate. 


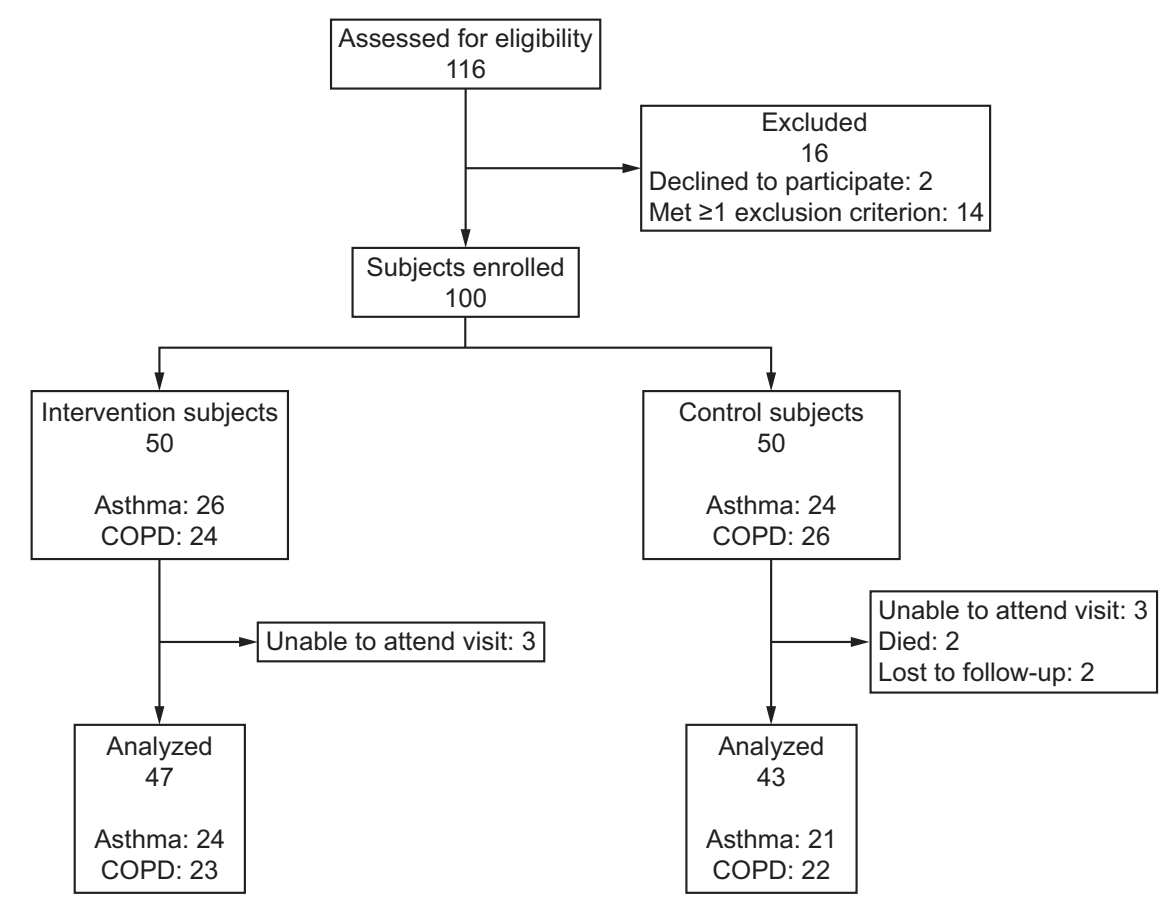

Fig. 1. Flow chart.

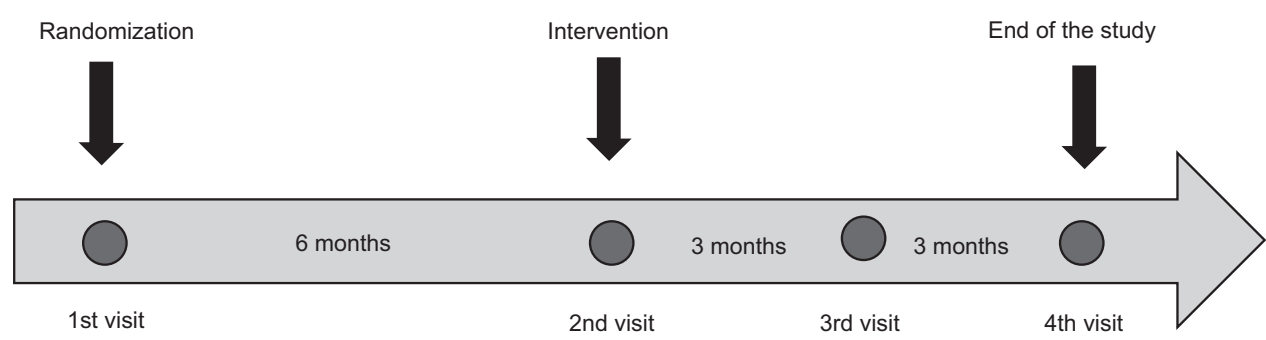

Fig. 2. Study timeline.

\section{Subjects}

The subjects were recruited from the out-patient department of the Central Teaching Hospital of the Medical University of Warsaw between 2013 and 2015. All consecutive subjects with asthma or COPD who were scheduled for a follow-up visit and who met the inclusion criteria were asked to participate in the study.

The main inclusion criteria were age between 18 and $80 \mathrm{y}$, earlier diagnosis of asthma or COPD made in accordance with GINA or GOLD recommendations, and at least 6 months of earlier treatment with at least 1 inhaler used daily on a regular basis. To reduce the heterogeneity of the group in terms of inhalers, only subjects treated with the following inhalers were included: pressurized metered dose inhaler (pMDI), Aerolizer, Handihaler, Diskus and Turbuhaler. The exclusion criteria included conditions and comorbidities that could affect the efficacy of training (eg, cognitive disorders, relevant mental or neurological dis- eases) or any condition causing the inability of the subject to attend a scheduled follow-up visit required by the study protocol (eg, advanced malignancies, severe chronic respiratory failure) (Fig. 1).

\section{Methods}

The study protocol included 4 visits over 12 months. At each visit, questionnaires on asthma/COPD symptom severity and the impact of the disease on quality of life were completed, the number of disease exacerbations since the last visit were noted, and the subject underwent physical examination and spirometry. Disease symptom severity was evaluated with the Asthma Control Test (ACT) in asthma subjects and with the COPD Assessment Test (CAT) in subjects with COPD. ${ }^{20,21}$ HRQOL was assessed using either the Asthma Quality of Life Questionnaire (AQLQ) or the St George's Respiratory Questionnaire (SGRQ). ${ }^{22,23}$ Only exacerbations that required treatment with oral cor- 
Table 1. Subject Characteristics

\begin{tabular}{|c|c|c|c|}
\hline & Treated Group & Control Group & $P$ \\
\hline Subjects & 50 & 50 & \\
\hline Age, y & $66.5(59-74)$ & $66(58-72)$ & .60 \\
\hline Sex, female/male & $27 / 23$ & $25 / 25$ & .69 \\
\hline Duration of the disease, $y$ & $10(5-15)$ & $10(4.25-17.75)$ & .61 \\
\hline Number of used inhalers & $3(2-3)$ & $3(2-3)$ & .50 \\
\hline Subjects who made at least one mistake during inhalation & 45 & 48 & .24 \\
\hline Subjects who made at least one critical mistake during inhalation & 40 & 40 & $>.99$ \\
\hline Smoking history, NS/S/EX & $26 / 8 / 16$ & $19 / 7 / 24$ & .25 \\
\hline Body mass index, $\mathrm{kg} / \mathrm{m}^{2}$ & $26.8(23.5-29.5)$ & $27.2(24.8-31)$ & .22 \\
\hline \multicolumn{4}{|l|}{ Asthma group $(n=50)$} \\
\hline Subjects & 26 & 24 & \\
\hline Age, y & $64.5(61-73)$ & $62(52-67)$ & .89 \\
\hline Sex, female/male & $16 / 8$ & $15 / 9$ & .76 \\
\hline Duration of the disease, $y$ & $10(3-14)$ & $14(6.75-27)$ & .41 \\
\hline Number of used inhalers & $2.5(2-3)$ & $3(2-3)$ & .54 \\
\hline Smoking history, NS/S/EX & $23 / 1 / 0$ & $15 / 3 / 3$ & .18 \\
\hline Body mass index, $\mathrm{kg} / \mathrm{m}^{2}$ & $27.1(25.6-29.9)$ & $28.4(25.8-32.2)$ & .14 \\
\hline Asthma Control Test & $15(11-21)$ & $17(14-20)$ & .82 \\
\hline $\mathrm{FEV}_{1} \% \mathrm{~N}$ & $78(61-88)$ & $75(66-86)$ & .89 \\
\hline$\% \mathrm{FEV}_{1} / \mathrm{FVC}<\mathrm{LLN}$ & $12 / 14$ & $11 / 13$ & .98 \\
\hline \multicolumn{4}{|l|}{$\operatorname{COPD}(n=50)$} \\
\hline Subjects & 24 & 26 & \\
\hline Age, y & $72(49-76)$ & $68.5(62-74)$ & .41 \\
\hline Sex, female/male & $9 / 15$ & $8 / 14$ & .94 \\
\hline Duration of the disease, $y$ & $10(3-13)$ & $10(3-13.5)$ & $>.99$ \\
\hline Number of used inhalers & $3(2-3)$ & $3(2-3)$ & .15 \\
\hline Smoking history, NS/S/EX & $1 / 7 / 16$ & $0 / 5 / 21$ & .70 \\
\hline Body mass index, $\mathrm{kg} / \mathrm{m}^{2}$ & $26.2(25.5-29.1)$ & $26.4(23.7-28.4)$ & .67 \\
\hline COPD Assessment Test & $19(14-23)$ & $12.5(8-23.5)$ & .09 \\
\hline $\mathrm{FEV}_{1} \% \mathrm{~N}$ & $52 \%(43-66)$ & $55 \%(36-68)$ & .84 \\
\hline $\begin{array}{l}\text { Data are presented as median (interquartile range) or numbers of subjects. } N=100 . \\
\text { Both groups were compared using chi-square test for categorical variables and Mann-W } \\
\text { NS = never smoker } \\
S=\text { smoker } \\
\text { EX }=\text { ex-smoker } \\
\text { FEV } V_{1} \% N=F E V_{1} \text { expressed as percentage of predicted value } \\
\text { LLN = lower limit of norm defined as below } 5 \text { th percentile }\end{array}$ & continuous variables. & & \\
\hline
\end{tabular}

ticosteroids and/or antibiotics, emergency department visit, or hospital admission were taken into consideration in the analyses. Spirometry was performed using the Lung Test 1000 spirometer (MES, Kraków, Poland); Global Lung Initiative reference equations were applied to calculate the predicted values. ${ }^{24}$

Inhalation technique was assessed at each visit by 2 observers: a trained medical student and pulmonologist. We evaluated 13 predefined inhalation errors for both pMDIs and dry powder inhalers (DPIs); 7 of them were construed as critical (Table 1, see the supplementary materials at http://www.rcjournal.com). The errors observed by the medical student and the pulmonologist were discussed, and consensus opinion was noted in the database. The number of mishandlings was calculated as the ratio of the number of errors to the number of inhalers used by an individual subject.

At the first visit, each subject was randomized 50:50 to the inhalation-training group or to the sham-procedure group (ie, given only the basic education on asthma or COPD). Computer-generated random numbers were used to allocate subjects, but no inhalation training or any modifications to the current asthma/COPD treatment were made; asthma/COPD treatment was at the discretion of the attending physician. The second visit was scheduled after 6 months. During this visit, basic education on asthma or COPD was carried out in both groups, along with the assessment of inhalation technique, which was followed by face-to-face training of proper inhalation technique in the intervention group and observation of inhalation tech- 
Table 2. The Effect of a Single Session of Inhalation Training on the Number of Mistakes and Other Variables Assessed After 3 Months (Intention-to-Treat Analysis)

\begin{tabular}{|c|c|c|c|c|}
\hline & Intervention Group & Control Group & Relative Risk & $P$ \\
\hline \multicolumn{5}{|l|}{ Number of mistakes during inhalation } \\
\hline Reduction & 32 & 20 & $1.63(1.10-2.42)$ & .01 \\
\hline No reduction & 16 & 29 & & \\
\hline No mistakes & 2 & 1 & & \\
\hline \multicolumn{5}{|c|}{ Number of asthma or COPD exacerbations } \\
\hline Reduction & 10 & 12 & $0.83(0.4-1.7)$ & .63 \\
\hline No reduction & 40 & 38 & & \\
\hline \multicolumn{5}{|c|}{ Number of asthma or COPD exacerbations requiring hospitalization } \\
\hline Reduction & 4 & 3 & $1.33(0.3-5.6)$ & .70 \\
\hline No reduction & 46 & 47 & & \\
\hline \multicolumn{5}{|l|}{ Symptoms measured by ACT or CAT } \\
\hline Reduction & 22 & 22 & $1.0(0.6-1.5)$ & $>.99$ \\
\hline No reduction & 28 & 28 & & \\
\hline \multicolumn{5}{|c|}{ Quality of life measured by AQLQ or SGRQ } \\
\hline Improvement & 17 & 11 & $1.54(0.8-2.9)$ & .19 \\
\hline Decrease & 33 & 39 & & \\
\hline \multicolumn{5}{|l|}{$\begin{array}{l}\text { Data are presented as numbers of patients or relati } \\
\text { ACT }=\text { Asthma Control Test } \\
\text { CAT }=\text { COPD Assessment Test } \\
\text { AQLQ }=\text { Asthma Quality of Life Questionnaire } \\
\text { SGRQ }=\text { St George's Respiratory Questionnaire }\end{array}$} \\
\hline
\end{tabular}

nique without error corrections in the sham-procedure group. The training of proper inhalation technique consisted of instruction and demonstration of proper inhaling technique respective to the type of inhaler used by the subject. Then subjects were asked to demonstrate a single inhalation, and persisting mishandlings were corrected. Training usually lasted 7-15 min, depending on the correctness of the inhalation technique.

During the third and fourth visits (3 mo after the second, and $3 \mathrm{mo}$ after the third visit, respectively), the subjects were examined by an observer blinded to randomization. The reduction in the severity of asthma or COPD symptoms, the number of disease exacerbations, and the number of inhalation mishandlings compared to visit 2 were noted (calculated as repeat baseline analysis). A subject was classified as a responder if he or she made fewer errors after training than before the intervention (ie, the ratio of the number of errors to the number of currently used inhalers was lower after intervention than baseline).

\section{Statistical Analysis}

Baseline data and the results of the study in intentionto-treat population are presented as median (interquartile range [IQR]) unless otherwise specified. Baseline characteristics and the results in the intervention versus control group were compared using the chi-squared test for categorical variables and the Mann-Whitney $U$ test for con- tinuous variables. All analyses were performed using Statistica 13.0 (StatSoft, Tulsa, Oklahoma) and MedCalc 13.2.2 (MedCalc Software bvba, Ostend, Belgium). A $P$ value $<.05$ was regarded as significant.

Based on the results of previous studies, we assumed that errors in inhalation technique are made by at least $35 \%$ of subjects, and we designed the current study to determine a reduction of $70 \%$ of errors between the 2 groups, with a standard deviation of $10 \% .{ }^{9}$ Power analysis and sample size calculations indicated that a sample size of 86 subjects would provide $90 \%$ statistical power to detect significant differences between the 2 groups (alpha $=0.05$, beta $=0.20$ ). The number of enrolled subjects was increased by 13 to allow for a $15 \%$ drop-out rate. Thus, a total number of 99 subjects was the minimum number required to conduct this study.

\section{Results}

A total of 100 subjects (50 with asthma, 50 with COPD) were enrolled in the study. Despite some differences between asthma and COPD subjects, the number of inhalers used per subject was similar in both groups (Table 2, see the supplementary materials at http://www.rcjournal.com). Comparative characteristics of subjects in the intervention and control groups (intention-to-treat population) are presented in Table 1. At the first visit, 93 of 100 subjects made at least 1 error during inhalation: 95\% (47 of 50) of 
subjects with asthma and 92\% (46 of 50) of subjects with COPD. There were no differences in the number of errors between the intervention and control group at baseline (Table 1). Critical errors occurred in $80 \%$ (80 of 100) of all subjects: 41 of 50 subjects with asthma and 39 of 50 subjects with COPD. Despite these results, 98 of 100 subjects considered their inhalation skills as satisfactory.

Ninety subjects completed the study; of the 10 subjects who failed to complete the study protocol, 8 did not attend the second visit ( 3 subjects from the intervention group and 5 subjects from the control group), and 2 subjects were lost to follow-up between the second and third visits. Among the subjects who were lost between the first and second visits, 2 subjects died (1 subject died due to complications of a myocardial infarction; the cause of death could not be determined in the other subject).

\section{The Effect of Intervention After 3 Months}

The effect of the intervention measured after 3 months was as follows: 32 of 50 subjects $(64 \%)$ in the intervention group and 20 of 50 (40\%) subjects in the control group had a lower ratio of errors during inhalation (Table 2). The relative risk was $1.63(P=.01)$ and number needed to treat was 3.9 (95\% CI 2.2-15).

Despite a reduction in the number of inhalation errors, we did not find a significant reduction in the number of asthma and COPD exacerbations, nor in the number of exacerbations requiring hospitalization (Table 2). A reduction in symptom severity was demonstrated in 44 subjects (22 subjects with asthma and 22 subjects with COPD), but no difference was found between the trained group and the control group (Table 2).

After the intervention, a similar proportion of subjects declared an improvement in HRQOL in each group (34\% vs $22 \%, P=.19)$. Overall, the improvement in quality of life was achieved only in 28 subjects (14 subjects with asthma and 14 subjects with COPD). No differences in HRQOL were found between the intervention group and the sham procedure group before and after the intervention when subjects with asthma and COPD were analyzed separately.

Comparative analysis of responders and non-responders showed that the latter made a priori fewer errors in inhalation technique than responders. No other differences between these groups were identified (Table 3). Comparable results were observed when a cut-off value of a $50 \%$ reduction in the number of mistakes was applied to define responders (results not shown).

\section{The Effect of Intervention After 6 Months}

After 6 months, there was no difference in the percentage of subjects who reduced the ratio of the numbers of errors to the number of inhalers in the intervention group and the control group ( $48 \%$ and $54 \%$, respectively, $P=.62$ ) (Table 4). Moreover, the effect of training decreased over time (Fig. 3). After 6 months from the intervention, the ratio of errors to inhaler remained stable or decreased in only $50 \%$ of the former responders to training (16 of 32 subjects).

There were no significant differences in the number of subjects who had fewer exacerbations, nor in the number of exacerbations between the intervention group and controls. Nonetheless, a tendency to a lower number of exacerbations requiring emergency department visits was observed in the intervention group (Table 3, see the supplementary materials at http://www.rcjournal.com). The reduction of respiratory symptoms was comparable between groups. There were also no significant differences between the intervention group and the control group in improvement of HRQOL (Table 4).

\section{Discussion}

Our study confirmed that the majority of adult subjects with asthma or COPD make at least 1 inhalation error and that a single short inhalation training session may lead to a reduction of the number of mistakes, but not necessarily to an improvement in asthma or COPD control. As the investigated subjects were randomly assigned to the study or control group and physicians assessing the effect of training were blinded to the earlier intervention (inhalation training or sham procedure), we believe our results are reliable, although the number of errors made by the subjects was higher than we had expected on the basis of the literature on the issue. Although the majority of subjects were convinced that they used good inhalation technique, the number of errors was higher than previously reported. This finding emphasizes that inhaler mishandling is still a common problem that seems to require more attention than just one short inhalation technique training.

Our results are consistent with a recent review from the Cochrane Library on different interventions used to improve inhaler technique in asthma subjects. ${ }^{25}$ They are also in agreement with the results of several other studies that documented the effectiveness of inhalation training in the reduction of inhaler misuse in both asthma and COPD. ${ }^{26,27-30}$ The role of proper inhalation technique is emphasized in all documents on the management of obstructive lung diseases. ${ }^{1-4}$ It seems easy to understand and convincing that improper inhalation may lead to inadequate treatment of asthma or COPD. ${ }^{9}$ On the other hand, the majority of subjects make errors when using their inhaler, ${ }^{13,31-33}$ and according to our previous studies, the majority of inhalation errors are repetitive. ${ }^{34}$ Moreover, despite the awareness of the problem, the frequency of improper inhalation technique has been constant 
Table 3. Comparison of Selected Parameters in Responders and Nonresponders to Inhalation Training (Assessment 3 Months After Training)

\begin{tabular}{|c|c|c|c|}
\hline & Responders & Nonresponders* & $P$ \\
\hline Age, y & $66.5(60.5-73)$ & $69(50-75)$ & .61 \\
\hline Female/male & $19 / 13$ & $7 / 6$ & .73 \\
\hline Asthma/COPD & $14 / 18$ & $9 / 4$ & .12 \\
\hline Duration of the disease, $y$ & $9.5(3.5-13)$ & $11(6-18)$ & .14 \\
\hline Number of inhalers & $3(2-3)$ & $3(2-3)$ & .44 \\
\hline \multicolumn{4}{|l|}{ Quality of life } \\
\hline Asthma: AQLQ & $5.45(4.3-5.9)$ & $4.9(3-6.3)$ & .36 \\
\hline COPD: SGRQ & $47.7(39-55.9)$ & $50.7(44.4-53.7)$ & .90 \\
\hline \multicolumn{4}{|l|}{ Symptom severity } \\
\hline Asthma: ACT score & $20.5(19-22)$ & $20(14-21)$ & .35 \\
\hline COPD: CAT score & $15(9-23)$ & $16(14.7-16.7)$ & .77 \\
\hline \multicolumn{4}{|l|}{ Spirometry: $\mathrm{FEV}_{1} \%$ predicted } \\
\hline Asthma & $77.8(65-88.4)$ & $78.4(55.2-85.1)$ & .53 \\
\hline COPD & $53(47.2-65.8)$ & $47.7(44.8-54)$ & .64 \\
\hline \multicolumn{4}{|l|}{ Spirometry: FVC \% predicted } \\
\hline Asthma & $86.2(75.2-95.2)$ & $84(78-101.3)$ & .73 \\
\hline COPD & $79.8(70-87.9)$ & $92.3(81.4-105.4)$ & .22 \\
\hline \multicolumn{4}{|l|}{ Spirometry: $\mathrm{FEV}_{1} / \mathrm{FVC}$} \\
\hline Asthma & $76.1(68.2-77.9)$ & $67.3(62.1-72.3)$ & .08 \\
\hline COPD & $55(47-58,7)$ & $42.1(39.1-44.9)$ & .10 \\
\hline Mistakes during inhalation with MDI, no. & $2(1-3)$ & $0.5(0-1.25)$ & .01 \\
\hline Mistakes during inhalation with DPI, no. & $2(1-2.75)$ & $1(0-1)$ & .008 \\
\hline All mistakes, no. & $4(2-5.5)$ & $1(1-2)$ & $<.001$ \\
\hline Ratio of errors during inhalation to all inhalers & $1.83(0.66-2.5)$ & $0.5(0.33-1)$ & $<.001$ \\
\hline Exacerbations that required hospitalizations, no. & $3(9.4 \%)$ & $2(15.4 \%)$ & .56 \\
\hline Exacerbation-related ED visits, no. & $2(6.2 \%)$ & $3(25 \%)$ & .10 \\
\hline Exacerbations that required oral GCS or antibiotic, no. & $12(37.5 \%)$ & $6(46.2 \%)$ & .59 \\
\hline $\begin{array}{l}\text { Data are presented as median (interquartile range) or number of patients. } \\
n=13 \text { subjects. } \\
* 2 \text { patients, who made no mistakes before and after training, were exclud } \\
\text { ACT }=\text { Asthma Control Test } \\
\text { CAT = COPD Assessment Test } \\
\text { AQLQ = Asthma Quality of Life Questionnaire } \\
\text { SGRQ = St George's Respiratory Questionnaire } \\
\text { DPI = dry powder inhaler } \\
\text { MDI = metered-dose inhaler } \\
\text { ED = emergency department } \\
\text { GCS = glucocorticosteroids }\end{array}$ & npared using the Mann-V & re test. Responders, $n=3$ & ders; \\
\hline
\end{tabular}

for 40 years. ${ }^{6}$ This indicates that the problem of improving inhalation technique is difficult to manage and goes beyond teaching manual skills.

There have been numerous observational studies showing the relationship between inhalation technique and control of asthma and COPD. ${ }^{9-13}$ Takemura and colleagues ${ }^{11,12}$ found that repeating proper inhalation instruction could improve not only inhalation technique, but also quality of life in both asthma and COPD. The same author group reported that a network pharmacist system can provide successful training of proper inhalation technique, increase adherence to therapy, and decrease the number of disease exacerbations. ${ }^{35,36}$ Another multi-center study performed in Italy demonstrated that inhaler misuse was common in subjects with asthma or COPD independent of the type of inhaler, and that it was associated with poor disease con- trol and increased risk of exacerbation. ${ }^{9}$ In a study by Molimard et al, ${ }^{10}$ the risk of COPD exacerbation requiring hospitalization or emergency department visit was 1.86 times higher in subjects who made critical inhalation errors compared to those who used inhalers correctly. It must be noted, however, that it is unclear whether the association between better control of the disease and better inhalation technique found in the above observational studies resulted from inhalation training or from other factors. Poor inhalation technique frequently coexists with poor adherence to treatment. ${ }^{37,38}$ Patients with better control of asthma or less severe COPD may have been better motivated to perform adequate inhalation technique and adhere to all treatment recommendations. ${ }^{38}$

In contrast to observational studies, there were only a few randomized controlled trials that confirmed the effect 
Table 4. Impact of a Single Session of Inhalation Technique Training on the Course of Asthma and COPD After 6 Months (Intention to Treat Analysis)

\begin{tabular}{|c|c|c|c|c|}
\hline & $\begin{array}{l}\text { Intervention } \\
\text { Group }\end{array}$ & $\begin{array}{l}\text { Control } \\
\text { Group }\end{array}$ & $\begin{array}{c}\text { Relative } \\
\text { Risk }\end{array}$ & $P$ \\
\hline \multicolumn{5}{|c|}{ Subjects who reduced mistakes during inhalation, $n$} \\
\hline Reduction & 24 & 27 & $0.91(0.62-1.32)$ & .62 \\
\hline No reduction & 24 & 22 & & \\
\hline No mistakes & 2 & 1 & & \\
\hline \multicolumn{5}{|l|}{ Subjects who had fewer exacerbations, $n$} \\
\hline Reduction & 8 & 4 & $2.00(0.64-6.22)$ & .23 \\
\hline No reduction & 42 & 46 & & \\
\hline \multicolumn{5}{|c|}{ Subjects who had fewer exacerbations requiring hospitalization, $n$} \\
\hline Reduction & 1 & 1 & $1.0(0.06-15.5)$ & $>.99$ \\
\hline No reduction & 49 & 49 & & \\
\hline \multicolumn{5}{|c|}{ Subjects who had fewer symptoms measured by ACT or CAT, $n$} \\
\hline Reduction & 16 & 22 & $0.73(0.43-1.21)$ & .22 \\
\hline No reduction & 34 & 28 & & \\
\hline \multicolumn{5}{|c|}{ Subjects who had higher quality of life measured by AQLQ or SGRQ, $n$} \\
\hline Improvement & 27 & 20 & $1.35(0.88-2.06)$ & .17 \\
\hline Decrease & 23 & 30 & & \\
\hline \multicolumn{5}{|c|}{$\begin{array}{l}\text { Data are presented as numbers of subjects and relative risk }(95 \% \mathrm{CI}) \text {. Each group } \\
\text { ACT }=\text { Asthma Control Test } \\
\text { CAT = COPD Assessment Test } \\
\text { AQLQ }=\text { Asthma Quality of Life Questionnaire } \\
\text { SGRQ = St George's Respiratory Questionnaire }\end{array}$} \\
\hline
\end{tabular}

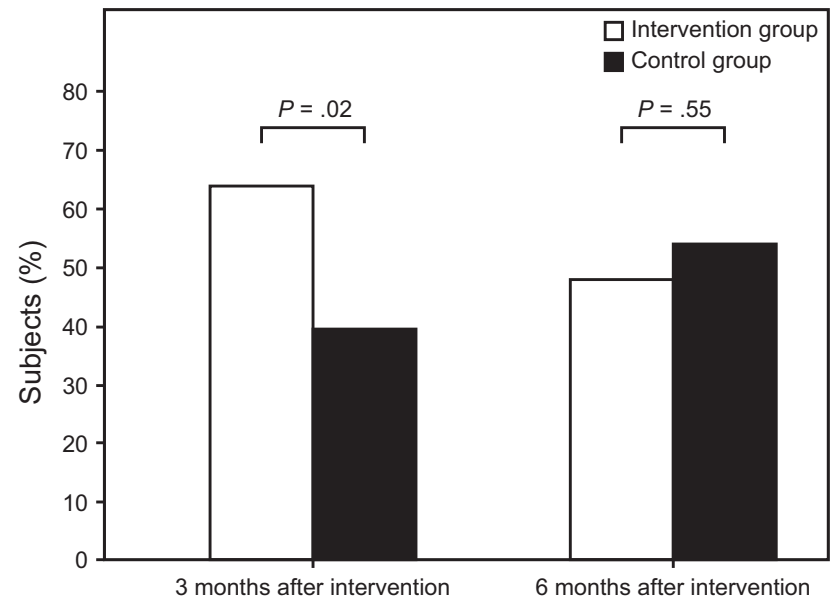

Fig. 3. Percentage of subjects who improved their inhalation technique after training. Data were compared using Mann-Whitney $U$ test.

of inhalation technique training on improvement in COPD or asthma control. ${ }^{14-19}$ The favorable effect was documented mainly in subjects with asthma. ${ }^{16-18}$ In studies including both subjects with asthma and subjects with COPD, the influence of inhalation counseling was less convincing. ${ }^{15,19}$ In a study by Press et al, ${ }^{14}$ teach-to-goal inhalation training led to a reduction of inhalation errors and unplanned interventions during the $30 \mathrm{~d}$ of follow-up in both subjects with asthma and subjects with COPD. The benefit of in- halation technique training was also found in two studies by Basheti et al, ${ }^{16,17}$ who observed improvement in inhalation skills and reduction in asthma severity after proper inhalation technique training. Garcia-Cardenas et al ${ }^{18}$ reported that an intervention consisting of education of inhalation technique and medication adherence led to an improvement in inhalation technique and better asthma control measured with Asthma Control Questionnaire in subjects with asthma who used the Turbuhaler (the study was sponsored by AstraZeneca). Although the above studies reported positive effects of inhalation training, they also showed a failure of some interventions. Press et al ${ }^{15}$ found that the effect of inhalation training was only temporary and did not lead to reduction of asthma or COPD exacerbations after $90 \mathrm{~d}$. Of note, the $90-\mathrm{d}$ observation revealed a similar incidence of exacerbations despite significantly decreased inhaler misuse. This finding does not support the hypothesis that improvement in inhalation technique can reduce the risk of asthma/COPD exacerbations. Similar results were reported by Hesselink et al, ${ }^{19}$ who observed that inhalation skills training in subjects with asthma and subjects with COPD resulted in better inhalation technique after 1 year and 2 years, but it did not influence symptoms, HRQOL, or smoking cessation.

In our study, almost all of the subjects made $\geq 1$ mistake during inhalation, and $80 \%$ of them made $\geq 1$ critical error. This result is higher than those reported in previously published studies in which critical errors were made 
by $12-50 \%$ of inhaler users depending on the inhaler type. $5,10,13,26,33,39$ However, there are also studies that show a frequency of inhaler mishandling similar to that in our study. Molimard et al ${ }^{32}$ noted that almost $77 \%$ of pMDI users made $\geq 1$ error, and Chorao et $\mathrm{al}^{40}$ reported that only $18 \%$ of subjects used inhalers without any mistake. In other studies, $>80 \%$ of subjects made $\geq 1$ error during inhalation. ${ }^{41,42}$

The high percentage of inhalation errors in our study may result from the investigated population or from the method used to assess the inhalation technique. The population in our study included only adults with a median age of $66.5 \mathrm{y} ; 53 \%$ of the subjects were $>65 \mathrm{y}$ old. The investigated subjects with asthma included patients with moderate and severe disease, none of the subjects from this group presented with mild disease. In addition, the majority of our subjects presented with poor disease control that was reflected by the low median ACT score in subjects with asthma (median 17, IQR 11-21) or a relatively high CAT score (median 17, IQR 11-23.7). At least a third $(35 \%)$ of all the investigated subjects had $\geq 1$ severe exacerbation during 6 months prior to the study onset. This may have been attributed to the fact that the subjects had been recruited from our out-patient clinic in which mainly patients who require specialist care (ie, with severe or difficult-to-treat asthma or COPD) are being treated. On the other hand, older subjects may be more likely to have problems with proper drug inhalation due to comorbidities, particularly neurological and vision disorders. It is worth emphasizing that almost all subjects were satisfied with their inhalation skills, what indicates that they were unaware of the problem. A similar disproportion was described by other authors. ${ }^{32}$

The high percentage of errors during inhalation in our study may have also been related to the method used to evaluate the inhalation technique. Despite numerous studies on inhalation therapy, to date no consensus has been established on how to assess errors in inhalation technique and which errors should be regarded as critical., ${ }^{825}$ Based on previous publications, we used a checklist of errors. $4,9,16,17$ This method has been used frequently, but it may overestimate the prevalence of incorrect use of inhaler devices because it considers all steps of inhaler use as a potential source of an important error. Currently, the analysis of the number of subjects who demonstrate good inhalation technique seems more adequate than using the checklist scores. ${ }^{25}$ However, as the above data were not available before 2017, we used checklists that seemed to be more objective. ${ }^{43}$ Other authors have used several different methods, such as the evaluation of critical errors only, ${ }^{4,9}$ grading systems, ${ }^{6,31}$ or grading devices. ${ }^{42,44,45}$ All of these methods have disadvantages and limitations.

The effect of our single, face-to-face training was significant but not spectacular (relative risk 1.63). It might have indicated that a single training session was not sufficient, despite our efforts to improve the inhalation technique of all the individual subjects. The training was performed face-to-face by an experienced pulmonologist with 20 years of experience in respiratory medicine. Each session usually lasted for 7-15 min and included verbal instruction, a demonstration, and practice of proper inhalation technique by the subject. The more errors that were present in inhalation technique, the more time was devoted to the training session. According to the recently published study by Melani et al, ${ }^{46} 5-7$ min of training should be sufficient to teach patients. The demonstration of proper inhalation technique seems to play a key role. ${ }^{47-49}$ Therefore, we concentrated on this aspect of training. Unfortunately, we did not use any method of quantitative feedback in checking inhalation technique, which seems a useful method to improve effectiveness of this type of education. ${ }^{45}$ The higher than expected percentage of our subjects who made critical inhalation errors and the smaller than expected effect of inhalation skills training may be a cause of lack of improvement in asthma or COPD course after intervention.

The reduction in the number of errors in our study was smaller than that found in studies included in Cochrane Library Review in which the odds ratio reached 4.8-5.0.25 We suppose that a single training session is not enough to eradicate the errors. A temporary effect of inhalation technique training has already been observed. ${ }^{17,50}$ This observation was confirmed by Takaku et al, ${ }^{44}$ who found that inhalation training should be repeated $\geq 3$ times to achieve good inhalation skills in $>90 \%$ of subjects with asthma or COPD. Similarly, in a recent study by Bosnic-Anticevic et al, ${ }^{51} 2$ or 3 training steps were necessary to achieve mastery in inhalation technique even in health care professionals. The effect of a single inhalation training decreased after 6 months in our study. A similar tendency was observed by other authors, emphasizing the role of repeated individual training of inhalation technique at each visit. ${ }^{47}$ Improving inhaler technique needs to be a regular and ongoing process.

Interestingly, we observed a higher median number of inhalation errors in responders than in non-responders to inhalation training. This refers to the use of both pMDI and DPI. Although it may seem a paradox, this phenomenon likely results from classifying subjects who reduced the ratio of errors per inhaler after training as responders without setting a cut-off point for the value of the reduction. Therefore, it may be easier to partially improve inhalation technique in subjects who make many mistakes than to eradicate all errors in subjects who make only few errors during inhalation. We also cannot exclude the concept that not all mistakes influence the quality of inhalation technique to the same degree. This emphasizes the need to establish objective measures for the evaluation of 
inhalation technique and calls for a clear definition of critical inhalation errors. ${ }^{8}$ Recently, critical inhaler mistakes have been identified for a number of the most commonly used inhalers, but only for patients with asthma. ${ }^{52}$

There are several limitations of our study. This was a single-center study that included a relatively small number of subjects who were observed only for 6 months after the intervention. Moreover, according to the inclusion criteria, only subjects using the most common inhalers (ie, pMDI, Aerolizer, Handihaler, Diskus or Turbuhaler) were recruited. The investigated group may not be representative of all patients with asthma or COPD given that more than half of our subjects were $>65 \mathrm{y}$ old and the majority presented with poor disease control. We cannot exclude that the response to inhalation technique training could be affected by age-related cognitive impairment. Therefore, it seems that studies on the impact of cognitive abilities on the effect of inhalation technique training in the elderly are warranted. Moreover, our results should be validated in younger patients with asthma and COPD patients. The fact that we used checklist scores to analyze inhalation errors, which could overestimate their number, may also be considered a limitation. Furthermore, we did not check the validity and reproducibility of the assessment of errors at repeated visits, nor did we use any quantitative feedback in checking inhaler technique. Despite these limitations, we believe that the results of our study are important because they indicate a link between better inhalation skills and less severe course of asthma or COPD.

\section{Conclusion}

Errors in inhalation technique are common in subjects with asthma as well as in subjects with COPD. A single short training in inhalation technique may lead to a reduction in the number of errors, but it may not necessarily lead to an improvement in disease control. The effect of a single training session is temporary, which may indicate that improving inhaler technique needs to be a regular and ongoing process.

\section{REFERENCES}

1. Global Initiative for Asthma. Global Strategy for Asthma Management and Prevention 2017. Available at: www.ginasthma.org. Accessed March 1, 2018.

2. British Thoracic Society. British guideline on the management of asthma 2016. Available at: www.brit-thoracic.org.uk/document-library/clinicalinformation/asthma/btssign-asthma-guideline-2016. Accessed March 1, 2018.

3. Global Initiative for Chronic Obstructive Lung Disease. Global Strategy for the Diagnosis, Management, and Prevention of Chronic Obstructive Pulmonary Diseases. Report 2018. Available at: www. goldcopd.org. Accessed March 1, 2018.

4. Inhaler Error Steering Committee, Price D, Bosnic-Anticevich S, Briggs A, Chrystyn H, Rand C, et al. Inhaler competence in asthma: common errors, barriers to use and recommended solutions. Respir Med 2013;107(1):37-46.

5. Laube BL, Janssens HM, de Jongh FH, Devadason SG, Dhand R, Diot $\mathrm{P}$, et al. What the pulmonary specialist should know about the new inhalation therapies. Eur Respir J 2011;37(6):1308-1331.

6. Sanchis J, Gich I, Pedersen S, Aerosol Drug Management Improvement T. Systematic review of errors in inhaler use: has patient technique improved over time? Chest 2016;150(2):394-406.

7. Rootmensen GN, van Keimpema AR, Jansen HM, de Haan RJ. Predictors of incorrect inhalation technique in patients with asthma or COPD: a study using a validated videotaped scoring method. J Aerosol Med Pulm Drug Deliv 2010;23(5):323-328.

8. Usmani OS, Lavorini F, Marshall J, Dunlop WCN, Heron L, Farrington $\mathrm{E}$, et al. Critical inhaler errors in asthma and COPD: a systematic review of impact on health outcomes. Respir Res 2018; 19(1):10

9. Melani AS, Bonavia M, Cilenti V, Cinti C, Lodi M, Martucci P, et al. Inhaler mishandling remains common in real life and is associated with reduced disease control. Respir Med 2011;105(6):930938.

10. Molimard M, Raherison C, Lignot S, Balestra A, Lamarque S, Chartier A, et al. Chronic obstructive pulmonary disease exacerbation and inhaler device handling: real-life assessment of 2935 patients. Eur Respir J 2017;49(2)

11. Takemura M, Kobayashi M, Kimura K, Mitsui K, Masui H, Koyama $\mathrm{M}$, et al. Repeated instruction on inhalation technique improves adherence to the therapeutic regimen in asthma. J Asthma 2010;47(2): 202-208.

12. Takemura M, Mitsui K, Itotani R, Ishitoko M, Suzuki S, Matsumoto $\mathrm{M}$, et al. Relationships between repeated instruction on inhalation therapy, medication adherence, and health status in chronic obstructive pulmonary disease. Int J Chron Obstruct Pulmon Dis 2011;6: 97-104.

13. Lavorini F, Magnan A, Dubus JC, Voshaar T, Corbetta L, Broeders $\mathrm{M}$, et al. Effect of incorrect use of dry powder inhalers on management of patients with asthma and COPD. Respir Med 2008;102(4): 593-604.

14. Press VG, Arora VM, Shah LM, Lewis SL, Charbeneau J, Naureckas ET, et al. Teaching the use of respiratory inhalers to hospitalized patients with asthma or COPD: a randomized trial. J Gen Intern Med 2012;27(10):1317-1325.

15. Press VG, Arora VM, Trela KC, Adhikari R, Zadravecz FJ, Liao C, et al. Effectiveness of interventions to teach metered-dose and Diskus inhaler techniques. a randomized trial. Ann Am Thorac Soc 2016;13(6):816-824.

16. Basheti IA, Armour CL, Bosnic-Anticevich SZ, Reddel HK. Evaluation of a novel educational strategy, including inhaler-based reminder labels, to improve asthma inhaler technique. Patient Educ Couns 2008;72(1):26-33.

17. Basheti IA, Obeidat NM, Reddel HK. Effect of novel inhaler technique reminder labels on the retention of inhaler technique skills in asthma: a single-blind randomized controlled trial. NPJ Prim Care Respir Med 2017;27(1):9.

18. Garcia-Cardenas V, Sabater-Hernandez D, Kenny P, Martinez-Martinez F, Faus MJ, Benrimoj SI. Effect of a pharmacist intervention on asthma control. A cluster randomised trial. Respir Med 2013;107(9): 1346-1355

19. Hesselink AE, Penninx BW, van der Windt DA, van Duin BJ, de Vries P, Twisk JW, et al. Effectiveness of an education programme by a general practice assistant for asthma and COPD patients: results from a randomised controlled trial. Patient Educ Couns 2004;55(1): 121-128. 
20. Nathan RA, Sorkness CA, Kosinski M, Schatz M, Li JT, Marcus P, et al. Development of the asthma control test: a survey for assessing asthma control. J Allergy Clin Immunol 2004;113(1):59-65.

21. Jones PW, Harding G, Berry P, Wiklund I, Chen WH, Kline Leidy N. Development and first validation of the COPD Assessment Test. Eur Respir J 2009;34(3):648-654.

22. Juniper EF, Buist AS, Cox FM, Ferrie PJ, King DR. Validation of a standardized version of the Asthma Quality of Life Questionnaire. Chest 1999;115(5):1265-1270.

23. Jones PW, Quirk FH, Baveystock CM, Littlejohns P. A self-complete measure of health status for chronic airflow limitation. The St. George's Respiratory Questionnaire. Am Rev Respir Dis 1992;145(6): 1321-1327.

24. Quanjer PH, Stanojevic S, Cole TJ, Baur X, Hall GL, Culver BH, et al. Multi-ethnic reference values for spirometry for the 3-95-yr age range: the global lung function 2012 equations. Eur Respir J 2012; 40(6):1324-1343.

25. Normansell R, Kew KM, Mathioudakis AG. Interventions to improve inhaler technique for people with asthma. Cochrane Database Syst Rev 2017;3:CD012286.

26. Leiva-Fernandez J, Leiva-Fernandez F, Garcia-Ruiz A, Prados-Torres D, Barnestein-Fonseca P. Efficacy of a multifactorial intervention on therapeutic adherence in patients with chronic obstructive pulmonary disease (COPD): a randomized controlled trial. BMC Pulm Med 2014;14:70.

27. Basheti IA, Reddel HK, Armour CL, Bosnic-Anticevich SZ. Improved asthma outcomes with a simple inhaler technique intervention by community pharmacists. J Allergy Clin Immunol 2007;119(6): $1537-1538$

28. Barnestein-Fonseca P, Vazquez-Alarcon R, Leiva-Fernandez F, Aguiar-Leiva V, Lobnig-Becerra M, Leiva-Fernandez J. Tecepoc II Study. How to improve the inhalation techniques in patient with COPD. The influence of preferences. Value Health 2014;17(7):A599A600.

29. Giner J, Macian V, Hernandez C, Grupo E. [Multicenter prospective study of respiratory patient education and instruction in the use of inhalers (EDEN study)]. Arch Bronconeumol 2002;38(7):300-305.

30. Dantic D. A critical review of the effectiveness of 'teach-back' technique in teaching COPD patients self-management using respiratory inhalers. Health Educ J 2014;73:41-50.

31. Press VG, Arora VM, Shah LM, Lewis SL, Ivy K, Charbeneau J, et al. Misuse of respiratory inhalers in hospitalized patients with asthma or COPD. J Gen Intern Med 2011;26(6):635-642.

32. Molimard M, Raherison C, Lignot S, Depont F, Abouelfath A, Moore $\mathrm{N}$. Assessment of handling of inhaler devices in real life: an observational study in 3811 patients in primary care. J Aerosol Med 2003;16(3):249-254.

33. Cochrane MG, Bala MV, Downs KE, Mauskopf J, Ben-Joseph RH. Inhaled corticosteroids for asthma therapy: patient compliance, devices, and inhalation technique. Chest 2000;117(2):542-550.

34. Luczak-Wozniak K, Dabrowska M, Domagala I, Miszczuk M, Lubanski W, Leszczynski A, et al. Mishandling of pMDI and DPI inhalers in asthma and COPD: repetitive and non-repetitive errors. Pulm Pharmacol Ther 2018;51:65-72.

35. Takemura M, Mitsui K, Ido M, Matsumoto M, Koyama M, Inoue $\mathrm{D}$, et al. Impact of a network system for providing proper inhalation technique by community pharmacists. J Asthma 2012;49(5): 535-541.
36. Takemura M, Mitsui K, Ido M, Matsumoto M, Koyama M, Inoue D, et al. Effect of a network system for providing proper inhalation technique by community pharmacists on clinical outcomes in COPD patients. Int J Chron Obstruct Pulmon Dis 2013;8:239-244.

37. Makela MJ, Backer V, Hedegaard M, Larsson K. Adherence to inhaled therapies, health outcomes and costs in patients with asthma and COPD. Respir Med 2013;107(10):1481-1490.

38. Bosnic-Anticevich SZ. Inhaler device handling: have we really started to address the problem? Eur Respir J 2017;49(2):1700120.

39. Westerik JA, Carter V, Chrystyn H, Burden A, Thompson SL, Ryan $\mathrm{D}$, et al. Characteristics of patients making serious inhaler errors with a dry powder inhaler and association with asthma-related events in a primary care setting. J Asthma 2016;53(3):321-329.

40. Chorao P, Pereira AM, Fonseca JA. Inhaler devices in asthma and COPD-an assessment of inhaler technique and patient preferences. Respir Med 2014;108(7):968-975.

41. Arora P, Kumar L, Vohra V, Sarin R, Jaiswal A, Puri MM, et al. Evaluating the technique of using inhalation device in COPD and bronchial asthma patients. Respir Med 2014;108(7):992-998.

42. Shealy KM, Paradiso VC, Slimmer ML, Campbell DL, Threatt TB. Evaluation of the prevalence and effectiveness of education on metered-dose inhaler technique. Respir Care 2017;62(7):882-887.

43. Basheti IA, Bosnic-Anticevich SZ, Armour CL, Reddel HK. Checklists for powder inhaler technique: a review and recommendations. Respir Care 2014;59(7):1140-1154.

44. Takaku Y, Kurashima K, Ohta C, Ishiguro T, Kagiyama N, Yanagisawa $\mathrm{T}$, et al. How many instructions are required to correct inhalation errors in patients with asthma and chronic obstructive pulmonary disease? Respir Med 2017;123:110-115.

45. Toumas-Shehata M, Price D, Basheti IA, Bosnic-Anticevich S. Exploring the role of quantitative feedback in inhaler technique education: a cluster-randomised, two-arm, parallel-group, repeated-measures study. NPJ Prim Care Respir Med 2014;24:14071.

46. Melani AS, Bonavia M, Mastropasqua E, Zanforlin A, Lodi M, Martucci $\mathrm{P}$, et al. Time required to rectify inhaler errors among experienced subjects with faulty technique. Respir Care 2017;62(4): 409-414.

47. Bosnic-Anticevich SZ, Sinha H, So S, Reddel HK. Metered-dose inhaler technique: the effect of two educational interventions delivered in community pharmacy over time. J Asthma 2010;47(3):251256.

48. Axtell S, Haines S, Fairclough J. Effectiveness of various methods of teaching proper inhaler technique. J Pharm Pract 2017;30(2):195201.

49. Price D, Keininger DL, Viswanad B, Gasser M, Walda S, Gutzwiller FS. Factors associated with appropriate inhaler use in patients with COPD - lessons from the REAL survey. Int J Chron Obstruct Pulmon Dis 2018;13:695-702.

50. Ovchinikova L, Smith L, Bosnic-Anticevich S. Inhaler technique maintenance: gaining an understanding from the patient's perspective. J Asthma 2011;48(6):616-624.

51. Bosnic-Anticevich S, Callan C, Chrystyn H, Lavorini F, Nikolaou V, Kritikos $\mathrm{V}$, et al. Inhaler technique mastery and maintenance in healthcare professionals trained on different devices. J Asthma 2018; 55(1):79-88.

52. Price DB, Roman-Rodriguez M, McQueen RB, Bosnic-Anticevich S, Carter V, Gruffydd-Jones K, et al. Inhaler errors in the CRITIKAL Study: type, frequency, and association with asthma outcomes. J Allergy Clin Immunol Pract 2017;5(4):1071-1081. 